\title{
PENGARUH APLIKASI SISTEM INFORMASI PELAYANAN PERIZINAN TERPADU (SIPINTER) TERHADAP KEPUASAN PELANGGAN DI DINAS PENANAMAN MODAL DAN PELAYANAN TERPADU SATU PINTU (DPMPTSP) KABUPATEN TANGERANG
}

\author{
Ricca Rosalinda 1 \\ H. Achmad Murodi, Drs., MM ${ }^{2}$ \\ Irvan Arif Kurniawan, S.Sos., M.AP. \\ Universitas Islam Syekh-Yusuf Tangerang \\ Email : riccarosalinda97@gmail.com
}

\begin{abstract}
This thesis is titled "The Effect of the Application of Integrated Licencing Service Information System (SIPINTER) on Customer Satisfaction in the Investment Service and One-Stop Integrated Service (DPMPTSP) of Tangerang District". The population in this study is the people who use Application SIPINTER in the Investment Service and One-Stop Integrated Service (DPMPTSP) of Tangerang District amount of 1,337 people from which in the whole population the researchers used 93 people as samples to be tested. This is indicated by the results of testing using the SPSS (Statistical Product and Solution Service) which shows a significant level of 0,000 which means smaller than 0,05 and $t$ count of 7,656 which is greater than t table that is 1,986. This situation shows that Ho was rejected and Ha was accepted, so the hypothesis that the researchers proposed proved correct. The conclusion is that there is a positive and significant effect between the Integrated Licensing Service Information System (SIPINTER) Application on Customer Satisfaction in the Investment Office and the One-Stop Integrated Service (DPMPTSP) of Tangerang District.
\end{abstract}

Keywords: Management Information System, Customer Satisfaction, Licensing

\begin{abstract}
ABSTRAK
Skripsi ini berjudul "Pengaruh Aplikasi Sistem Informasi Pelayanan Perizinan Terpadu (SIPINTER) Terhadap Kepuasan Pelanggan di Dinas Penanaman Modal dan Pelayanan Terpadu Satu Pintu (DPMPTSP) Kabupaten Tangerang". Populasi pada penelitian ini adalah masyarakat yang menggunakan Aplikasi SIPINTER di Dinas Penanaman Modal dan Pelayanan Terpadu Satu Pintu (DPMPTSP) Kabupaten Tangerang berjumlah 1.337 orang yang selanjutnya dari seluruh populasi tersebut peneliti menggunakan 93 orang sebagai sampel untuk diuji. Hal ini ditunjukkan oleh hasil pengujian menggunakan SPSS (Statistical Product and Solution Service) yang menunjukkan tingkat signifikan 0,000 yang berarti lebih kecil dari 0,05 dan t hitung sebesar 7,656 yang lebih besar dari t tabel yaitu 1,986. Keadaan ini menunjukkan bahwa Ho ditolak dan Ha diterima, jadi hipotesis yang peneliti ajukan terbukti kebenarannya. Kesimpulannya adalah terdapat pengaruh positif dan signifikan antara Aplikasi Sistem Informasi Pelayanan Perizinan Terpadu (SIPINTER) Terhadap Kepuasan Pelanggan di Dinas Penanaman Modal dan Pelayanan Terpadu Satu Pintu (DPMPTSP) Kabupaten Tangerang.
\end{abstract}

Kata Kunci : Sistem Informasi Manajemen, Kepuasan Pelanggan, Perizinan 


\section{PENDAHULUAN}

Teknologi informasi berperan dalam menunjang kegiatan-kegiatan organisasi, oleh sebab itu banyak organisasi modern membangun dan mengembangkan sistem informasi manajemennya sendiri. Sejak dulu,

Sistem Informasi Manajem tersebut sebenarnya sudah dikenal namun proses penanganannya masih menggunakan sistem manual. Sedangkan pada saat ini proses penanganan Sistem Informasi Manajemen

sudah memanfaatkan kemajuan dan perkembangan teknologi informasi dengan menggunakan sistem komputerisasi ataupun aplikasi lainnya.

Pemerintah Kabupaten Tangerang melaunching layanan aplikasi publik secara online yaitu Sistem Informasi Pelayanan Perizinan Terpadu (SIPINTER) pada tanggal 27 Desember 2017, sebagai upaya Pemda Kabupaten Tangerang untuk meningkatkan

kemudahan, kecepatan dan efisiensi pelayanan kepada masyarakat dalam hal pelayanan perizinan. Salah satu aspek yang perlu dilakukan perubahan adalah aspek sistem informasi dari Dinas Penanaman Modal dan Pelayanan Terpadu Satu Pintu (DPMPTSP) Kabupaten Tangerang.

Kepuasan Pelanggan sangatlah penting sebagai penilaian pelanggan terhadap jasa atau pelayanan yang telah memberikan tingkat kenikmatan seperti yang diharapkan, setiap kegiatan dalam hal pelayanan yang berkaitan dengan kepuasan pelanggan maka kelangsungan penyedia layanan yaitu Dinas Penanaman Modal dan Pelayanan Terpadu

Satu Pintu (DPMPTSP) Kabupaten Tangerang pun akan terjaga. Oleh sebab itu apabila seseorang bertanggungjawab terhadap kepuasan pelanggan dan berupaya memuaskan kebutuh pelanggan, maka akan terjadi sesuatu yang lebih baik untuk dimasa akan datang.

Berdasarkan pengamatan sementara, ditemukan beberapa masalah yang menunjukkan kurang optimalnya menggunakan Aplikasi Sistem Informasi Pelayanan Perizinan Terpadu (SIPINTER), antara lain :

1. Kurang optimalnya proses mengupload berkas persyaratan bagi pelanggan untuk membuat perizinan usaha.

2. Masih belum efektif jika Pelanggan terlalu banyak dalam proses pendaftaran perizinan akan memperlambat koneksi jaringan.

3. Masih belum responsive melalui android untuk tampilan login Sistem Informasi Pelayanan Perizinan Terpadu (SIPINTER) dan hanya melalui Personal Computer (PC).

4. Dikarenakan ada peralihan izin-izin usaha dari Sistem Informasi Pelayanan Perizinan Terpadu (SIPINTER) terhadap aplikasi baru yaitu Online Single Submission (OSS) maka terhambatnya proses pembuatan perizinan usaha. 


\section{TINJAUAN PUSTAKA}

\section{Sistem Informasi Manejemen}

\section{a. PengertianSistemInformasi}

\section{Manajemen}

Menurut Gordon B. Davis yang dikutip oleh Ahmad dan Munawir (2018:14) bahwa, "Sistem Informasi Manejemen adalah sebuah sistem manusia atau mesin yang terpadu untuk menyajikan informasi guna mendukung fungsi operasi manajemen dan pengambilan keputusan dalam suatu organisasi”.

\section{b. Faktor - faktor yang mempengaruhi}

\section{Sistem Informasi Manajemen}

Menurut Hamidjoyo, Santoso S. (2000) yang dikutip oleh Darmawan dan Fauzi (2016:7) bahwa, "Informasi pembelajaran yang dikelola melalui Sistem Informasi manajemen (SIM) ini diharapkan mampu memenuhi karakterisitik". Karakteristik yang dimaksud diatas dapat diuraikan sebagai berikut :

1) Kuantitas Informasi (Amount of Information)

2) Kualitas Informasi (Quality of Information)

3) Informasi Aktual (Recency of Information)

4) Informasi yang Relevan atau Sesuai (Relevance of Information)

5) Ketepatan Informasi (Accuracy of Information)

6) Kebenaran Informasi (Autehnticity of Information) c. Pengertian Sistem Informasi

Pelayanan Perizinan Terpadu (SIPINTER)

Menurut Winarno dan Iswari (2018:2) menjelaskan bahwa, "Dengan adanya sistem informasi yang baru, maka pelayanan penanaman modal dan perizinan akan dapat diselenggarakan dengan baik, sebagai salah satu bentuk aplikasi Sistem Informasi Pelayanan Perizinan Terpadu (SIPINTER). Manfaat menerapkan Sistem terbaru ini, di Dinas Penanaman Modal dan Pelayanan Terpadu Satu Pintu dapat meningkatkan kemudahan, kecepatan, dan efisiensi pelayanan kepada masyarakat dalam hal penanaman modal dan perizinan usaha, sehingga berdampak pada peningkatan pertumbuhan ekonomi, pembukaan lapangan kerja, serta kesejahteraan mayarakat di Kabupaten Tangerang".

\section{Pengertian Pelayanan}

Menurut Kasmir (2017:47) menjelaskan bahwa, "Pelayanan diartikan sebagai tindakan atau perbuatan seseorang atau organisasi untuk memberikan kepuasan kepada pelanggan atau sesama karyawan".

\section{Kepuasan Pelanggan}

$$
\begin{aligned}
& \text { a. Pengertian Kepuasan Pelanggan } \\
& \text { Menurut Kotler dikutip oleh Kasmir } \\
& (2017: 236) \text { bahwa, "Kepuasan Pelanggan } \\
& \text { merupakan penilaian dari pelanggan atas } \\
& \text { penggunaan barang ataupun jasa } \\
& \text { dibandingkan dengan harapan sebelum } \\
& \text { penggunaannya". }
\end{aligned}
$$




\section{b. Faktor - faktor yang mempengaruhi}

\section{Kepuasan Pelanggan}

Menurut Parasuraman, dkk dalam Tjiptono dan Gregorius (2005) dikutip

Nugroho dan Magnadi (2018:3) menjelaskan bahwa, "Untuk mengukur sebuah layanan dikatakan berkualitas atau tidak, terdapat lima (5) dimensi kualitas jasa”. Yaitu sebagai berikut :

1) Kehandalan (Reliability)

2) Daya Tanggap (Responsiveness)

3) Jaminan (Assurance)

4) Empati (Emphaty)

5) Bukti Fisik (Tangibles)

\section{METODOLOGI PENELITIAN}

\section{Metode Penelitian}

Menurut Sugiyono (2018:2) menjelaskan bahwa, "Metode penelitian pada dasarnya merupakan cara ilmiah untuk mendapatkan data dengan tujuan dan kegunaan tertentu".

Kemudian menurut Sugiyono (2018:11) menjelaskan bahwa, "Peneliti kuantitatif dalam melihat hubungan variabel terhadap obyek yang diteliti lebih bersifat sebab dan akibat (kausal), sehingga dalam penelitiannya ada variabel independen dan dependen".

Dari variabel tersebut, selanjutnya dicari seberapa besar pengaruh variabel independen (X) terhadap variabel dependen (Y). Dan dalam penelitian ini, metode yang digunakan peneliti adalah metode asosiatif.

\section{Populasi dan Sampel}

\section{a. Populasi}

MenurutPasolong(2012:100)

menjelaskan bahwa, "Populasi adalah keseluruhan atau universe yang karakteristik-karakteristiknya data diamati untuk ditarik menjadi suatu sampel dalam penelitian".

Berdasarkan dari pemahaman tersebut, maka peneliti menggunakan populasi yang berjumlah 1.337 pelanggan di Dinas Penanaman Modal dan Pelayanan Terpadu Satu Pintu (DPMPTSP) Kabupaten Tangerang. Untuk mengetahui jumlah pelanggan berdasarkan pada bulan Januari - Juli 2018, maka peneliti menyajikan pada tabel sebagai berikut :

TABEL 3.1

JUMLAH PELANGGAN BERDASARKAN PADA BULAN JANUARI - JULI TAHUN 2018

\begin{tabular}{|l|c|c|c|}
\hline No. & Bulan & $\begin{array}{c}\text { Jumlah } \\
\text { Pelanggan }\end{array}$ & Persentase \% \\
\hline 1. & Januari & 14 & $1 \%$ \\
\hline 2. & Februari & 256 & $19 \%$ \\
\hline 3. & Maret & 290 & $22 \%$ \\
\hline 4. & April & 299 & $22 \%$ \\
\hline 5. & Mei & 265 & $20 \%$ \\
\hline 6. & Juni & 104 & $8 \%$ \\
\hline 7. & Juli & 109 & $8 \%$ \\
\hline $\begin{array}{l}\text { Jumlah } \\
\text { Keseluruhan }\end{array}$ & 1.337 & $100 \%$ \\
\hline \multicolumn{2}{|l|}{ Sul| }
\end{tabular}

Sumber : Dinas Penanaman Modal dan

Pelayanan Terpadu Satu Pintu Tahun 2018 


\section{b. Sampel}

Menurut Sugiyono (2014:81) dikutip oleh Suryani (2019:267) menjelaskan bahwa, "Sampel adalah sebagian dari jumlah dan karakteristik yang dimiliki oleh populasi tersebut".

Teknik yang digunakan dalam penelitian ini yaitu menggunakan Teknik

Sampling Kebetulan (Accidental Sampling). Menurut Sugiyono dikutip oleh Pasolong (2012:107) menjelaskan bahwa, "Teknik sampling kebetulan (Accidental Sampling) yaitu suatu teknik penarikan sampel yang paling sederhana, karena peneliti memperoleh sampel dengan cara kebetulan saja di lokasi penelitian dengan tidak menggunakan perencanaan tertentu".

Karena jumlah pelanggan di Dinas Penanaman Modal dan Pelayanan Terpadu Satu Pintu berjumlah 1.337 pelanggan, maka peneliti menggunakan rumus Slovin pada pelanggan di Dinas Penanaman Modal dan Pelayanan Terpadu Satu Pintu Kabupaten Tangerang.

Adapun dalam penelitian ini peneliti mengambil jumlah sampel menggunakan rumus Slovin.

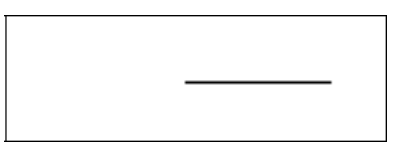

Keterangan :

$\mathrm{n} \quad=$ Ukuran Sampel

$\mathrm{N}=$ Ukuran Populasi

$\mathrm{e}=$ Presentase kelonggaran sampel yang

masih dapat ditoleransi
Diketahui :

$$
\begin{aligned}
& 1=\text { Konstanta } \\
& \mathrm{n}=\text { Ukuran Sampel } \\
& \mathrm{N}=1.337 \\
& \mathrm{e}^{2}=10 \% \\
& \mathrm{n}=\frac{1.337}{1+1.337\left(10 \%^{2}\right)} \\
& \mathrm{n}=\frac{1.337}{1+1.337(0,01)} \\
& \mathrm{n}=\frac{1.337}{1+13,37} \\
& \mathrm{n}=\frac{1337}{14,37}=93,04=93 \text { Orang }
\end{aligned}
$$

Dengan demikian, jumlah sampel adalah 93 responden, dari jumlah keseluruhan populasi yang sebanyak 1.337 pelanggan, dan yang menjadi responden adalah pelanggan di Dinas Penanaman Modal dan Pelayanan Terpadu Satu Pintu (DPMPTSTP) Kabupaten Tangerang.

\section{Operasional Variabel}

Menurut Kerlinger (1996:51) yang dikutip oleh Pasolong (2013:88) bahwa, "Definisi operasional adalah meletakkan arti pada suatu konstruk atau variabel dengan menetapkan kegiatan-kegiatan atau tindakan-tindakan yang perlu untuk mengukur konstruk atau variabel itu".

\section{Instrumen Penelitian}

MenurutSugiyono(2018:102)

menjelaskan bahwa, "Instrumen penelitian adalah suatu alat yang digunakan mengukur fenomena alam maupun sosial yang diamati”. Secara spesifik semua fenomena ini disebut 
variabel penelitian. Instrumen digunakan

dalam pengumpulan data terdiri dari :

\section{a. Jenis Sumber Data}

1) Menurut Sugiyono $\quad$ (2018:137) menjelaskan bahwa, "Sumber primer adalah sumber data yang langsung memberikan data kepada pengumpul data".

2) KemudianmenurutSugiyono

(2018:137) menjelaskan bahwa, "Sumber sekunder merupakan sumber yang tidak langsung memberikan data kepada pengumpul data, misalnya lewat orang lain atau lewat dokumen”.

\section{b. Teknik Pengumpulan Data}

1) Studi Kepustakaan yaitu pengumpulan data dilakukan dengan mempelajari dan menganalisa buku-buku, teori melalui literature kepustakaan, atau bahan-

bahan tertulis lainnya yang berhubungan dengan penelitian yang dilakukan.

2) Studi Lapangan yaitu melalui penelitian langsung pada obyek penelitian untuk memperoleh data-data secara langsung dari sumbernya dengan instrumen sebagai berikut :

- Observasi

- Interview (Wawancara)

- Kuesioner (Angket)
5. Uji Validitas, Reliabilitas dan Normalitas Data

\section{a. Uji Validitas}

Pengujianinidilakukanuntuk

mengetahui apakah pertanyaan (instrumen) penelitian yang diajukan untuk mengukur variabel penelitian adalah valid.

\section{b. Uji Reliabilitas}

Pengujian Reliabilitas digunakan untuk mengukur konsistensi jawaban responden.

\section{c. Uji Normalitas}

Penggunaan statistik parametris, bekerja dengan asumsi bahwa setiap variabel penelitian yang akan dianalisis membentuk distribusi normal. Bila data tidak normal, maka teknik statistik parametris tidak dapat digunakan untuk analisis.

\section{Teknik Analisa Data dan Pengujian}

\section{Hipotesis}

\section{a. Uji Koefisien Korelasi}

Analilisinidigunakanuntuk

mengetahui pengaruh kedua variabel, yakni antara variabel Sistem Informasi Manajemen (X) dan variabel Kepuasan Pelanggan (Y). Maka rumus yang digunakan adalah korelasi product moment.

b. Uji Koefisien Determinasi $\left(\mathbf{r}^{2}\right)$

Uji koefisien Determinasi, yaitu untuk mengukur seberapa besar variabel-variabel bebas dapat menjelaskan variabel terikat, digunakan koefisien multi korelasi atau koefisien determinasi $\left(\mathrm{r}^{2}\right)$. 


\section{c. Uji Regresi Linear Sederhana}

Persamaan regresi linear dapat

digunakan untuk melakukan prediksi seberapa tinggi nilai variabel dependen bila nilai variabel independen. Regresi linier sederhana didasarkan pada hubungan fungsional atau kausal satu variabel bebas dengan satu variabel terikat.

\section{d. Uji Hipotesis ( $t_{\text {hitung }}$ )}

Uji hipotesis dapat didasarkan dengan menggunakan dua hal, yaitu tingkat signifikan atau probabilitas $(\alpha)$ dan tingkat kepercayaan atau confidence interval.

\section{HASIL PENELITIAN DAN}

\section{PEMBAHASAN}

\section{A. Variabel X (Aplikasi Sistem Informasi}

\section{Pelayanan Perizinan Terpadu} (SIPINTER))

\section{1) Kuantitas Informasi}

Berdasarkan hasil observasi dari penerima pelayanan Aplikasi SIPINTER yaitu indikator Kuantitas Informasi terdapat 37 responden dengan presentase $39,8 \%$ memberikan tanggapan Setuju. Hal ini dikarenakan Kuantitas Informasi dalam Aplikasi SIPINTER mampu mengutamakan hasil informasi sistem pelayanan dalam memenuhi kebutuhan pelanggan. Dan untuk meningkatkan Aplikasi SIPINTER sebaiknya hasil informasi yang diberikan kepada pelanggan dalam pembuatan perizinan usaha harus lebih ditingkatkan lagi.

\section{2) Kualitas Informasi}

Berdasarkan hasil observasi dari penerima pelayanan Aplikasi SIPINTER yaitu indikator Kualitas Informasi terdapat 35 responden dengan presentase $37,6 \%$ memberikan tanggapan Kurang Setuju. Hal ini dikarenakan Kualitas Informasi dalam Aplikasi SIPINTER kurang mampu memberikan informasi sistem pelayanan dalam memenuhi kebutuhan pelanggan. Dan untuk meningkatkan Aplikasi SIPINTER sebaiknya informasi yang diberikan kepada pelanggan dalam pembuatan perizinan usaha harus bermutu atau sesuai dengan kebutuhan pelanggan.

\section{3) Informasi Aktual}

Berdasarkan hasil observasi dari penerima pelayanan Aplikasi SIPINTER yaitu indikator Informasi Aktual terdapat 36 responden dengan presentase $38,7 \%$ memberikan tanggapan Setuju. Hal ini dikarenakan Informasi Aktual dalam

Aplikasi SIPINTER mampu mengutamakan informasi sistem pelayanan yang terbaru atau bersifat $U p$ to Date

kepada pelanggan. Dan untuk meningkatkan Aplikasi SIPINTER sebaiknya lebih ditingkatkan lagi terutama informasi yang aktual atau terkini untuk memperlancar pembuatan perizinan usaha pelanggan.

\section{4) Informasi yang Relevan atau Sesuai}

Berdasarkan hasil observasi dari penerima pelayanan Aplikasi SIPINTER yaitu indikator Informasi yang Relevan 
atau Sesuai terdapat 34 responden dengan presentase $36,6 \%$ memberikan tanggapan Kurang Setuju. Hal ini dikarenakan Informasi yang Relevan atau Sesuai dalam Aplikasi SIPINTER kurang mampu dalam memberikan informasi sistem pelayanan yang berkaitan dengan kebutuhan pelanggan. Dan untuk meningkatkan Aplikasi SIPINTER seharusnya lebih ditingkatkan lagi informasi yang sesuai kaitannya dengan proses pembuatan perizinan usaha bagi pelanggan agar berjalan dengan baik.

\section{5) Ketepatan Informasi}

Berdasarkan hasil observasi dari penerima pelayanan Aplikasi SIPINTER yaitu indikator Ketepatan Informasi terdapat 35 responden dengan presentase $37,6 \%$ memberikan tanggapan Kurang Setuju. Hal ini dikarenakan Ketepatan Informasi dalam Aplikasi SIPINTER kurang tepat dalam menginformasikan sitem pelayanan untuk kebutuhan pelanggan. Dan untuk meningkatkan Aplikasi SIPINTER seharusnya lebih ditingkatkan lagi dalam ketepatan informasi guna kelancaran proses pembuatan perizinana usaha bagi pelanggan.

\section{6) Kebenaran Informasi}

Berdasarkan hasil observasi dari penerima pelayanan Aplikasi SIPINTER yaitu indikator Kebenaran Informasi terdapat 36 responden dengan presentase $38,7 \%$ memberikan tanggapan Setuju. Hal ini dikarenakan Kebenaran Informasi dalam Aplikasi SIPINTER mampu mengutamakan informasi sitem pelayanan yang benar adanya untuk kebutuhan pelanggan. Dan untuk meningkatkan Aplikasi SIPINTER sebaiknya ada peningkatan lagi, berkaitan dengan informasi yang benar agar proses pembuatan perizinan usaha akan tetap berjalan dengan baik dan meminimalisir kesalahan.

\section{B. Variabel Y (Kepuasan Pelanggan)}

\section{1) Kehandalan (Reliability)}

Berdasarkan hasil observasi dari penerima pelayanan Kepuasan Pelanggan yaitu indikator Kehandalan (Reliablity) terdapat 37 responden dengan presentase $39,8 \%$ memberikan tanggapan Setuju. Hal ini dikarenakan Kehandalan dalam

Kepuasan Pelanggan mampu mengutamakan sistem pelayanan yang diberikan oleh pegawai seperti : tepat waktu, cepat dan mudah bagi pelanggan. Dan untuk meningkatkan kehandalan bagi Dinas Penanaman Modal dan Pelayanan Terpadu Satu Pintu (DPMPTSP) Kabupaten Tangerang sebaiknya ditingkatkan lagi kinerja layanan sesuai dengan waktu yang sudah disepakati, tanpa membuat kesalahan.

\section{2) Daya Tangkap (Responsiveness)}

Berdasarkan hasil observasi dari penerima pelayanan Kepuasan Pelanggan yaitu indikator Daya Tangkap (Responsiveness) terdapat 36 responden 
dengan presentase 38,7\% memberikan tanggapan Kurang Setuju. Hal ini dikarenakan Daya Tangkap dalam Kepuasan Pelanggan kurang mampu dalam menangani keluhan atau permasalahan pelanggan. Dan untuk meningkatkan Daya Tangkap bagi Dinas Penanaman Modal dan Pelayanan Terpadu Satu Pintu

(DPMPTSP) Kabupaten Tangerang seharusnya lebih ditingkatkan dengan kesediaan pegawai memberikan bantuan, informasi yang jelas, dan merespon apa yang diinginkan pelanggan.

\section{3) Jaminan (Assurance)}

Berdasarkan hasil observasi dari penerima pelayanan Kepuasan Pelanggan yaitu indikator Jaminan (Assurance) terdapat 31 responden dengan presentase $33,3 \%$ memberikan tanggapan antara Kurang Setuju dan Setuju (Seimbang). Hal ini dikarenakan Jaminan dalam Kepuasan Pelanggan masih kurang maksimal dalam keakuratan, kecepatan data dan kurang memberikan rasa kepercayaan pelanggan untuk proses jasa pelayanan. Dan untuk meningkatkan Jaminan bagi Dinas Penanaman Modal dan Pelayanan Terpadu Satu Pintu (DPMPTSP) Kabupaten Tangerang seharusnya lebih ditingkatkan lagi dalam menumbuhkan kepercayaan pelanggan dan setiap pegawai selalu memberikan sikap dan etika yang baik guna menangani masalah proses jaminan pelayanan.

\section{4) Empati (Emphaty)}

Berdasarkan hasil observasi dari penerima pelayanan Kepuasan Pelanggan yaitu indikator Empati (Emphaty) terdapat 36 responden dengan presentase 38,7\% memberikan tanggapan Setuju. Hal ini dikarenakan Empati dalam Kepuasan Pelanggan mampu mengutamakan perhatian seperti : memahami, mendengarkan, dan menindaklanjuti keluhan terhadap pelanggan. Dan untuk meningkatkan Empati bagi Dinas Penanaman Modal dan Pelayanan Terpadu Satu Pintu (DPMPTSP) Kabupaten Tangerang sebaiknya lebih ditingkatkan lagi dalam memahami permasalahan dan bertindak sesuai dengan kepentingan pelanggan serta memberikan perhatian secara profesional.

\section{5) Bukti Fisik (Tangibles)}

Berdasarkan hasil observasi dari penerima pelayanan Kepuasan Pelanggan yaitu indikator Bukti Fisik (Tangibles) terdapat 37 responden dengan presentase 39,8\% memberikan tanggapan Setuju. Hal ini dikarenakan Bukti Fisik dalam

Kepuasan Pelanggan mampu mengutamakan sarana dan prasarana untuk kenyamanan, kerapihan, dan kelengkapan dalam mendukung kebutuhan pelanggan. Dan untuk meningkatkan Bukti Fisik bagi Dinas Penanaman Modal dan Pelayanan Terpadu Satu Pintu (DPMPTSP) Kabupaten Tangerang sebaiknya lebih ditingkatkan lagi untuk memberikan 
fasilitas yang lengkap dan tertata rapih guna menjadi daya tarik pelanggan agar merasa nyaman.

\section{KESIMPULAN DAN SARAN}

\section{a) Kesimpulan}

Berdasarkan rangkaian peneliti pada bab sebelumnya, peneliti akan membuat kesimpulan mengenai pembahasan

"Pengaruh Aplikasi Sistem Informasi Pelayanan Perizinan Terpadu (SIPINTER) terhadap Kepuasan Pelanggan di Dinas Penanaman Modal dan Pelayanan

\section{Terpadu Satu Pintu (DPMPTSP)}

Kabupaten Tangerang" sebagai berikut :

1. Hasil penelitian menunjukkan bahwa Aplikasi Sistem Informasi Pelayanan Perizinan Terpadu (SIPINTER) di Dinas Penanaman Modal dan Pelayanan Terpadu Satu Pintu (DPMPTSP) Kabupaten Tangerang yaitu sebesar $75 \%$ dari kriteria yang ditetapkan.

2. Tingkat Kepuasan Pelanggan di Dinas Penanaman Modal dan Pelayanan Terpadu Satu Pintu (DPMPTSP) Kabupaten Tangerang yaitu sebesar $75 \%$ dari kriteria yang ditetapkan.

3. Terdapat pengaruh yang kuat antara Aplikasi Sistem Informasi Pelayanan Perizinan Terpadu (SIPINTER) terhadap Kepuasan Pelanggan di Dinas Penanaman Modal dan Pelayanan Terpadu Satu Pintu (DPMPTSP) Kabupaten Tangerang berdasarkan hasil penelitian koefisien korelasi sebesar 0,626 atau 6,26\%.
4. Adapun untuk mengetahui besar kecilnya antara variabel $\mathrm{X}$ dan $\mathrm{Y}$ dihitung dengan menggunakan Koefisien Determinasi $\left(\mathrm{r}^{2}\right)=$ $0,626^{2}=0,392$ atau 39,2\% . Ini membuktikan variabel (X) Aplikasi Sistem Informasi Pelayanan Perizinan Terpadu (SIPINTER) memberikan kontribusi terhadap variabel (Y) Kepuasan Pelanggan sebesar 39,2\%.

\section{b) Saran}

Berdasarkan hasil kesimpulan, maka peneliti memberikan saran sebagai masukan kepada Dinas Penanaman Modal dan Pelayanan Terpadu Satu Pintu (DPMPTSP) Kabupaten Tangerang sebagai berikut :

1) Untuk meningkatkan pelayanan Aplikasi Sistem Informasi Pelayanan Perizinan Terpadu (SIPINTER) dalam proses mengupload berkas-berkas persyaratan pendaftaran perizinan usaha harus lebih dioptimalkan, agar berjalan dengan lancar dan pelanggan tidak merasakan kesulitan. Hal ini dikarenakan berhubungan dengan indikator variabel X (Kuantitas Informasi) yaitu mampu mengutamakan hasil informasi sistem pelayanan dalam memenuhi kebutuhan pelanggan.

2) Untuk mewujudkan pelayanan Aplikasi Sistem Informasi Pelayanan Perizinan Terpadu (SIPINTER) yang efektif perlu adanyakoordinasidalamproses

pendaftaran perizinan usaha yang melibatkan jika pelanggan terlalu banyak akan memperlambat koneksi jaringan, sebaiknya lebih terkoordinasi dan sistem 
harus diperbaharui dengan baik guna proses berjalan lancar sesuai dengan prosedur. Hal ini dikarenakan berhubungan dengan indikator variabel X (Informasi yang Relevan dan Sesuai) yaitu mampu memberikan informasi terhadap pelayanan yang kaitannya dengan kelancaran proses pembuatan perizinan usaha untuk pelanggan.

3) Untuk mempermudah pelayanan Aplikasi Sistem Informasi Pelayanan Perizinan Terpadu (SIPINTER) perlu direalisasikan dalam melakukan login aplikasi melalui android dan tidak hanya menggunakan komputer saja, agar meningkatkan informasi yang aktual dan terkini dalam proses pendaftaran izin-izin usaha. Hal ini dikarenakan berhubungan dengan indikator variabel $\mathrm{X}$ (Informasi Aktual) yaitu mampu mengutamakan informasi pelayanan yang terbaru atau bersifat $U p$ to Date kepada pelanggan.
4) Untuk mewujudkan sistem pelayanan yang lebih baik karena adanya peralihan data izin-izin usaha dari Aplikasi Sistem Informasi Pelayanan Perizinan Terpadu (SIPINTER) terhadap aplikasi baru yaitu Online Single Submission (OSS) yang menghambat proses pembuatan perizinan usaha, maka harus diintegrasikan secara cepat guna memperlancar proses pelayanan pengaksesan data perizinan. Hal ini dikarenakan berhubungan dengan indikator variabel X (Kualitas Informasi) yaitu mampu memberikan informasi yang berkualitas dan bermutu sesuai dengan kebutuhan pelanggan.

\section{DAFTAR PUSTAKA}

Ahmad, Lukman dan Munawir. Sistem Informasi Manajemen : Buku Referensi. Banda Aceh. Lembaga Komunitas Informasi Teknologi Aceh (KITA).

Anggara, Sahya. 2016. Ilmu Administrasi Negara. Bandung: CV Pustaka Setia.

Darmawan, Deni dan Fauzi, Kunkun Nur. 2016. Sistem Informasi Manajemen. Bandung: PT. Remaja Rosdakarya.

Hasibuan. Malayu. 2011. Manajemen Dasar, Pengertian dan Masalah. Jakarta: PT. Bumi Aksara. Hasibuan. Malayu. 2014. Organisasi dan Motivasi. Jakarta: PT. Bumi Aksara.

Kasmir. 2017. Customer Services Excellent. Jakarta: PT. Rajagrafindo Persada.

Moekijat. 1996. Pengantar Sistem Informasi Manajemen. Bandung: PT. Remaja Rosdakarya.

Pasolong, Harbani. 2012. Metode Penelitian Administrasi Publik. Bandung: Penerbit CV Alfabeta.

Pasolong, Harbani. 2013. Metode Penelitian Administrasi Publik. Bandung: Alfabeta

Priansa, Donni Juni. 2018. Manajemen Organisasi Publik. Bandung: CV Pustaka Setia.

Rusdiana dan Irfan. 2014. Sistem Informasi Manajemen. Bandung: CV Pustaka Setia. 
Sugiyono, Prof. Dr. 2018. Metode Penelitian Kuantitatif, Kualitatif, dan R\&D. Bandung: Penerbit CV Alfabeta.

Syafiie, Inu Kencana. 2015. Sistem Administrasi Negara Republik Indonesia (SANRI). Jakarta: PT. Bumi Aksara.

Syafri, Wirman. 2012. Studi Tentang Administrasi Publik. Bandung: PT. Gelora Aksara Pratama.

Wibowo. 2007. Edisi Kelima Manajemen Kinerja. Depok: PT. Rajagrafindo Persada.

\section{Jurnal-Jurnal :}

Aqil, Ibnu. 2010. "Sistem Informasi Alumni Program Diploma Pada Bina Sriwijaya Palembang Berbasis Web". Jurnal Iptek. Hal. 3.

Kurniawan, Irvan Arif. 2016. "Analisis Kualitas Pelayanan Transportasi Kereta Api Berdasarkan Konsep Paradigma New Public Service (NPS)”. Jurnal Ilmiah Ilmu Administrasi. Vol. 1; No. 1; 2016; Hal. 42.

Matondang, Zulkifli. 2009. "Validitas dan Reliabilitas Suatu Instrumen Penelitian”. Jurnal Publik. Vol. 6; No. 1; 2009; 87-97.

Musanto, Trisno. 2013. "Faktor-faktor Kepuasan Pelanggan dan Loyalitas Pelanggan". Jurnal Manajemen \& Kewirausahaan. Vol. 6; No. 2; 2004; 125

Nofyat, dkk. 2018. "Sistem Informasi Pengaduan Pelanggan Air Berbasis Website Pada PDAM Kota Ternate". Indonesian Journal on Information System. Vol. 3; No. 1; 2018; 13

Nugroho, Aji dan Magnadi, Rizal Hari. 2018. "Pengaruh Kualitas Layanan Terhadap Kepuasan Pelanggan Jasa Pengiriman Lazada Express saat Harbolnas di E-commerce”. Diponegoro Journal of Management. Vol. 7; No. 4; 2018; 3-4

Suminar, Ratna dan Apriliawati. 2017. "Pelayanan Prima Pada Orang Tua Siswa di Sempoa Sip Tc Paramount Summarecon". Jurnal Sekretari. Vol. 4; No. 2; 2017; 2.

Suryani, Lilis N. 2019. "Pengaruh Kompensasi Dan Lingkungan Kerja Terhadap Kinerja Karyawan PT. Indo Tekhnoplus”. Jurnal Ilmiah, Manajemen Sumber Daya Manusia. Vol. 2; No. 2; 2019; 267

Winarno, dan Iswari, Ni Made Satvika. 2018. "Implementasi Sistem Perizinan Online (Sipinter) Dinas Penanaman Modal dan Pelayanan Terpadu Satu Pintu Kabupaten Tangerang”. Jurnal Prosiding PKM-CSR. Vol. 1; 2018; 2.

Yola, Melfa dan Budianto, Duwi. 2013. “Analisis Kepuasan Konsumen Terhadap Kualitas Pelayanan dan Harga Produk Pada Supermarket dengan Menggunakkan Metode Importance Performance Analysis (IPA)”. Jurnal Optimasi Sistem Industri. Vol. 12; No. 12; 2013; 302

\section{Website :}

http://dpmptsp.tangerangkab.go.id/index.php (diakses April, 2019)

\section{Dokumen-Dokumen :}

Al-Qur'an, Surah Ali-Imran ayat 159

Al-Qur'an, Surah Hud Ayat 120

Peraturan Pemerintah Nomor 24 Tahun 2018 Tentang Pelayanan Perizinan Berusaha Terintegrasi Secara Elektronik

Peraturan Menteri Dalam Negeri Nomor 24 Tahun 2006 tentang Pedoman Penyelenggaraan Pelayanan Terpadu Satu Pintu

Peraturan Bupati Tangerang Nomor 95 Tahun 2016 tentang Kedudukan, Susunan Organisasi, Tugas dan Fungsi, serta Tata Kerja Dinas Penanaman Modal dan Pelayanan Terpadu Satu Pintu Kabupaten Tangerang 